\title{
A Predictive Cost Analysis Model for Estimating Formulary Impact of New Products in Managed Care
}

\author{
Samuel Hedayati, B. Pharm., Ph.D., and Peter W. Kleinstiver, Ph.D.
}

\begin{abstract}
Competition among new pharmaceutical products for unrestricted formulary inclusion continues to dominate the concerns of managed care decision makers. These competitive pressures may originate when a formulary appears to be overcrowded and underfunded based on what it is expected to deliver-primarily financial management of an ever-increasing list of new products in addition to day-to-day pharmaceutical needs. For those managers facing the daunting task of improving quality of pharmaceutical care with finite resources, appropriate product selection has become a dual consideration involving assessment of the new product's competitive clinical features and benefits, in tandem with an assessment of its formulary cost impact.

We present a simple and objective financial model that, based on historical utilization data, will help predict a priori an accurate estimate of the cost impact of a new product. We illustrate our financial model with a new calcium antagonist (CA), T-Block. T-Block is the first of a new
\end{abstract}

AUTHORS

SAMUEL HEDAYATI, B. PHARM., PH.D., is with the Healthcare Management Department, Roche Laboratories, Inc., Nutley, NJ, and PETER W. KLEINSTIVER, PH.D., is with Katalyst Professional Services, Inc., London, Ontario, Canada.

AUTHOR CORRESPONDENCE: Peter W. Kleinstiver, Ph.D., Katalyst Professional Services, Inc., 23 Carriage Hill Crescent, London, ON, Canada, N5X 3W8.

AUTHOR ACKNOWLEDGEMENT: The authors would like to thank Sandra J. Kleinstiver, A.R.T., for her assistance with preparation and critical review of the manuscript.

Copyright@ 1998 Academy of Managed Care Pharmacy, Inc. All rights reserved. generation of nondihydropyridine, T-channel selective CAs entering a crowded therapeutic area for the treatment of hypertension and angina pectoris. This model compares the weighted average cost-per-prescription for CAs before and after the formulary inclusion of T-Block. Three key variables of the model-utilization ratios of available strengths, market share for the new product, and annual CA prescription volume-facilitate preparation of customized financial analyses. Accordingly, the model's simple three-way sensitivity analysis defines specific financial scenarios under various conditions of uncertainty. The model also can be used as a post-formulary utilization management and market share tracking tool.

Key Words: Calcium antagonist, Drug utilization review, Formulary, Managed care, Pharmacoeconomics, Pharmacy benefits management, Reimbursement

J Managed Care Pharm 1998: 585-590

$\mathrm{I}$ $\mathrm{n}$ recent years, health care trends in the U.S. have included a remarkable reduction in patient length of stay, a significant contraction in the number of acute care beds, and a patients are treated on an outpatient/ambulatory basis. ${ }^{1}$ Competition among new therapeutic agents for unrestricted formulary access status has intensified, necessitating budgetary processes that subject new products to greater scrutiny. Managed care organizations that want to maintain the best possible standard of pharmaceutical care must use proactive thinking and planning, as well as aggressive budgeting, in making formulary decisions.

Upon regulatory approval, pharmaceutical companies may market new drugs. Compared with existing drugs, new agents have been used by significantly fewer patients. Therefore, true cost effectiveness is difficult, if not impossible, to determine until sufficient real-world experience is attained. Nonetheless, pharmacy benefit managers must decide whether to include these new drugs on formulary in advance of such effectiveness data. Typically, in coordination with the pharmacy department, pharmacy and therapeutics (P\&T) committees assess both the clinical (safety and efficacy) and financial impacts (cost effectiveness). of a new product before recommending or rejecting it for reimbursement. Evaluating the economic outcomes of a formulary candidate may involve a simple comparison of expenditures (cost avoidance) when two drugs have been deemed therapeutically equivalent. ${ }^{2}$ Formulary decisions also may involve 
Table 1. Required Format for Data Entry

\begin{tabular}{|c|c|c|c|c|c|c|c|c|c|}
\hline Generic Name & Mfr. & Trade Name & Strength & Form & $\begin{array}{c}\text { Number of } \\
\text { Prescriptions (Rx) }\end{array}$ & Quantity (units)* & $\begin{array}{c}\text { Total } \\
\mathrm{AWP}(\$)^{* *}\end{array}$ & $\begin{array}{c}\text { Market Share }(\$) \\
\% \text { Sub } \dagger\end{array}$ & $\begin{array}{c}\text { Market Share }(\$) \\
\% \text { Total } \neq\end{array}$ \\
\hline \multirow[t]{3}{*}{ Amlodipine } & Pfizer & Norvasc & $2.5 \mathrm{mg}$ & Tab & 18,329 & 804,403 & $\$ 981,396$ & $4.3 \%$ & $0.635 \%$ \\
\hline & & & $5 \mathrm{mg}$ & Tab & 262,649 & $11,823,617$ & $\$ 14,399,801$ & $63.3 \%$ & $9.311 \%$ \\
\hline & & & $10 \mathrm{mg}$ & $\mathrm{Tab}$ & 85,114 & $3,483,317$ & $\$ 7,353,735$ & $32.3 \%$ & $4.755 \%$ \\
\hline \multicolumn{10}{|c|}{ Total $=\$ 22,734,932$} \\
\hline \multirow[t]{4}{*}{ Diltiazem } & HMR & Cardizem & $30 \mathrm{mg}$ & $\mathrm{Tab}$ & 11,129 & $1,122,210$ & $\$ 511,299$ & $1.5 \%$ & $0.331 \%$ \\
\hline & & & $60 \mathrm{mg}$ & Tab & 9,777 & $1,003,961$ & $\$ 718,187$ & $2.1 \%$ & $0.464 \%$ \\
\hline & & & $90 \mathrm{mg}$ & Tab & 2,404 & 254,855 & $\$ 256,534$ & $0.7 \%$ & $0.166 \%$ \\
\hline & & & $120 \mathrm{mg}$ & $\mathrm{Tab}$ & 657 & 60,514 & $\$ 79,845$ & $0.2 \%$ & $0.052 \%$ \\
\hline
\end{tabular}

\footnotetext{
* Quantity=number of units (tablets, capsules, etc.) prescribed/dispensed on those prescriptions

** Total AWP $(\$)=$ total value of prescriptions for those strengths

$\dagger$ Market Share $(\$) \%$ Sub=market share as a percentage of total value of each subgroup of $C A$

$\mp$ Market Share $(\$) \%$ Total=market share as a percentage of total value of all CA prescriptions for the entire data set
}

more extensive cost-effectiveness studies ${ }^{3}$ for compounds that are similar, but not judged to be therapeutically equivalent. However, in the absence of cost-effectiveness data that reflect unrestricted utilization of a newly launched product, some decision makers may resort to a simple comparison of "negotiated" acquisition costs. This method, although convenient, tends to be time consuming and may involve offers and counteroffers (none of which may be directly comparable) from several parties. It tends to ignore historical patterns of drug utilization that reflect physician prescribing habits and underlying patient demographics, adjunct medication, and the availability of multiple strengths that may be priced differentially. In recognition of these limitations, other, more sensitive and convenient techniques of financial impact analysis are slowly emerging, particularly when a therapeutic area may be overcrowded. ${ }^{+}$

We present a robust, objective, and practical financial model that is designed to assist health care decision makers faced with difficult formulary alternatives. This model calculates (utilizing a weighted average method) a priori the cost impact of a new product. Using T-Block as an example, we illustrate that historical drug utilization data (prescriptions, units, average wholesale price), in addition to knowledge of prescribing dynamics, can be used to compare the weighted average cost-per-prescription before and after the formulary adoption of a new product. We also illustrate how a simple three-way sensitivity analysis generated from the same model can be used to define specific financiai goals under conditions of uncertainty, allowing decision makers to track post-formulary market penetration of a new drug.

\section{METHODS}

The financial model requires knowledge of historical utilization data for a specified time period, typically a minimum of one continuous financial quarter. It is based on estimation of the weighted average cost-per-prescription before and after the addition of a new product to the formulary. The model calculates a weighted average cost-per-prescription from utilization data of currently reimbursed products and a price parameter based on Average Wholesale Price (AWP), Wholesale Average Cost (WAC), or Net Sales (including all discounts/rebates). It then compares this mathematically representative average of the entire data set with its best estimate of the new product's weighted average cost-per-prescription. The weighted average cost-per-prescription for the new product is calculated using an average quantity-per-prescription dispensed for that category of products (in our example, calcium antagonists) and a price parameter based on AWP, WAC, or Net Sales. Finally, to determine the annual cost-impact of the new product, the difference between the weighted average cost-per-prescription before and after the formulary adoption of the new product (using identical AWP, WAC, or Net Sales pricing to compare the new product with established products) is annualized assuming different conditions of uncertainty. Specific steps in this cost analysis technique are detailed below.

\section{DATA ENTRY}

Table 1 illustrates the required format for data entry of last period CA utilization data for a specified time period. ${ }^{3}$ (All data are automatically annualized.)

Step 1. Calculation of the weighted average cost-per-prescription for each product and for the entire data set.

The weighted average costs-per-prescription for each product separately and for the entire data set are related parameters. The model calculates the weighted average cost-per-prescription for each product by dividing the total $\mathrm{AWP}(\$)$ for each strength of the product by the number of prescriptions $(\mathrm{Rx})$. The model then weights the result by multiplying the respective market share percentage in the subgroup, calculated by 
dividing total dollars for each strength by the total dollars in that generic subgroup. These results then are summed. The process of calculating the weighted average cost-per-prescription is repeated for each branded product.

\section{Example}

For Norvasc, the weighted average cost-per-prescription is equal to the weighted average cost-per-prescription of the $2.5 \mathrm{mg}$ strength plus the weighted average cost-per-prescription of the $5 \mathrm{mg}$ strength plus the weighted average cost-per-prescription of the $10 \mathrm{mg}$ stréngth.

$=[\$ 981,396($ Total AWP $(\$)) \div 18,329$ (Number of Rx) $\mathrm{x}$ $4.3 \%$ (Market Share(\$) \% Sub)]

$+[\$ 14,399,801$ (Total AWP $(\$)) \div 262,649$ (Number of $\mathrm{Rx}$ ) x 63.3\% (Market Share(\$) \% Sub)]

$+[\$ 7,353,735$ (Total AWP $(\$)) \div 85,114$ (Number of Rx) x. 32.3\% (Market Share(\$) \% Sub)]

$=\$ 64.91$

To calculate the weighted average cost-per-prescription for the entire data set, the above process is repeated for each product (by strength), and is weighted by its respective market share based on dollars as a percentage of the total. This is calculated by dividing total dollars for each strength by the total dollars in the entire data set, and then summed. Therefore:

Weighted average cost-per-prescription for the entire data set $=$

Average cost-per-prescription for Norvasc $\mathrm{x}$ Total market share +

Average cost-per-prescription for Cardizem $x$ Total market share +

Average cost-per-prescription for Procardia x Total market share +

Average cost-per-prescription for Calan $\mathrm{x}$ Total market share, etc.

\section{Example}

For Norvasc, its contribution to the weighted average cost-perprescription for the entire data set is calculated as in the previous example, except that market share as a percentage of total dollars is substituted for market share as a percentage of the subgroup:

$$
\begin{aligned}
= & {[\$ 981,396(\text { Total AWP }(\$)) \div 18,329(\text { Number of Rx }) \mathrm{x}} \\
& 0.634 \%(\text { Market Share }(\$) \% \mathrm{Tt})] \\
+ & {[\$ 14,399,801 \text { (Total AWP }(\$)) \div 262,649 \text { (Number of Rx) } } \\
& \times 9.306 \%(\text { Market Share }(\$) \% \mathrm{Tt} 1)] \\
+ & {[\$ 7,353,735(\text { Total AWP }(\$)) \div 85,114 \text { (Number of RX) }} \\
& \times 4.735 \%(\text { Market Share }(\$) \% \mathrm{Ttl})] \\
= & \$ 9.53
\end{aligned}
$$

\section{Example}

For Cardizem, its contribution to the weighted average costper-prescription for the entire data set is:

$$
=[\$ 511,299(\text { Total AWP }(\$)) \div 11,129 \text { (Number of } \mathrm{Rx}) \mathrm{x}
$$

Table 2. Average Quantity-Per-Prescription for Comparable Products

\begin{tabular}{l|c}
\hline \multicolumn{1}{c|}{ Product } & Average Quantity-Per-Prescription \\
\hline NorvasC & 44 \\
\hline Cardizem CD & 44 \\
\hline Plendil ER & 47 \\
\hline Procardia XL \& Adalat CC & 43 \\
\hline Calan SR & 49 \\
\hline Average for entire dataset & 44 \\
\hline
\end{tabular}

$0.330 \%$ (Market Share $(\$) \% \mathrm{Ttl})]$

$+[\$ 718,187$ (Total AWP $(\$))+9,777$ (Number of Rx) $x$ $0.464 \%$ (Market Share $(\$) \% \mathrm{Ttl})]$

$+[\$ 256,534$ (Total AWP $(\$)) \div 2,404$ (Number of Rx) $\mathrm{x}$ $0.166 \%$ (Market Share $(\$) \% \mathrm{Ttl}$ )]

$+[\$ 79,845$ (Total AWP $(\$)) \div 657$ (Number of Rx) $\mathrm{x}$ $0.052 \%$ (Market Share(\$) \% Ttl)]

$=\$ .73$

The contribution to the weighted average cost-per-prescription for the entire data set is repeated for all products and then summed. It is unique for each data set and is an important parameter since it will be used as a representative benchmark in the calculation of cost savings or cost increases resulting from the addition of a new, multi-strength product. The weighted average cost-per-prescription for this dataset (excluding T-Block) is $\$ 69.86$

\section{Step 2. Estimation of the weighted average cost-per-prescrip- tion for a new product (e.g., T-Block).}

The weighted average cost-per-prescription for the new tetralol calcium antagonist (T-Block) is calculated according to the following formula:

Weighted average cost-per-prescription of T-Block= Estimated quantity-per-prescription (number of units) of T-Block (2a)

$x$ Blended price of T-Block (2b)

\section{Step 2(a) Estimated quantity-per-prescription of T-Block.}

As expected, at the time of launch of a new product, little or no utilization data are available for entry into the model. In the absence of such data, the model assumes parameter 2(a) to be equal to the average quantity-per-prescription of other products that have a comparable dosing schedule to T-Block, and that T-Block most likely will displace. To accomplish this step, the model calculates an average quantity-per-prescription for Adalat CC, Procardia XL, Norvasc, Cardizem CD, Calan SR and Plendil. In this dataset, the average quantity-per-prescription is 44 (Table 2).

\section{Step 2(b) Blended price of T-Block.}

If a product is available in more than one strength, with 
Table 3. Sensitivity Analyses Showing Formulary Cost Impact of a New Product as Each Parameter Is Varied to Examine Conditions of Uncertainty

\begin{tabular}{|c|c|c|c|c|c|c|c|c|}
\hline \multirow{2}{*}{$\begin{array}{l}\text { Utilization Ratio } \\
\text { of T-Block } 50 \mathrm{mg} \\
\text { and } 100 \mathrm{mg} \\
\text { strengths }\end{array}$} & \multirow{2}{*}{$\begin{array}{c}\text { T-Block } \\
\text { Market Share } \\
\text { (prescriptions) }\end{array}$} & \multicolumn{3}{|c|}{ Decrease in Prescriptions } & \multirow{2}{*}{$\begin{array}{c}\text { No Change } \\
\text { in Total } \\
\text { Number of } \\
\text { Prescriptions }\end{array}$} & \multicolumn{3}{|c|}{ Increase in Prescriptions } \\
\hline & & $-15 \%$ & $-10 \%$ & $-5 \%$ & & $5 \%$ & $10 \%$ & $15 \%$ \\
\hline \multirow[t]{4}{*}{$90 \%: 10 \%$} & $0 \%$ & $\$ 0$ & $\$ 0$ & $\$ 0$ & $\$ 0$ & $\$ 0$ & $\$ 0$ & $\$ 0$ \\
\hline & $5 \%$ & $-\$ 1,186,136$ & $-\$ 1,255,909$ & $-\$ 1,325,681$ & $-\$ 1,395,454$ & $-\$ 1,465,227$ & $-\$ 1,535,000$ & $-\$ 1,604,772$ \\
\hline & $10 \%$ & $-\$ 2,372,272$ & $-\$ 2,511,818$ & $-\$ 2,651,363$ & $-\$ 2,790,908$ & $-\$ 2,930,454$ & $-\$ 3,069,999$ & $-\$ 3,209,545$ \\
\hline & $15 \%$ & $-\$ 3,558,408$ & $-\$ 3,767,726$ & $-\$ 3,977,044$ & $-\$ 4,186,363$ & $-\$ 4,395,681$ & $-\$ 4,604,999$ & $-\$ 4,814,317$ \\
\hline \multirow[t]{4}{*}{$80 \%: 20 \%$} & $0 \%$ & $\$ 0$ & $\$ 0$ & $\$ 0$ & $\$ 0$ & $\$ 0$ & $\$ 0$ & $\$ 0$ \\
\hline & $5 \%$ & $-\$ 776,305$ & $-\$ 821,970$ & $-\$ 867,635$ & $-\$ 913,300$ & $-\$ 958,965$ & $-\$ 1,004,630$ & $-\$ 1,050,295$ \\
\hline & $10 \%$ & $-\$ 1,552,610$ & $-\$ 1,643,940$ & $-\$ 1,735,270$ & $-\$ 1,826,600$ & $-\$ 1,917,930$ & $-\$ 2,009,260$ & $-\$ 2,100,590$ \\
\hline & $15 \%$ & $-\$ 2,328,915$ & $-\$ 2,465,910$ & $-\$ 2,602,905$ & $-\$ 2,739,900$ & $-\$ 2,876,895$ & $-\$ 3,013,890$ & $-\$ 3,150,885$ \\
\hline \multirow[t]{4}{*}{$70 \%: 30 \%$} & $0 \%$ & $\$ 0$ & $\$ 0$ & $\$ 0$ & $\$ 0$ & $\$ 0$ & $\$ 0$ & $\$ 0$ \\
\hline & $5 \%$ & $-\$ 367,506$ & $-\$ 389,124$ & $-\$ 410,742$ & $-\$ 432,360$ & $-\$ 453,978$ & $-\$ 475,596$ & $-\$ 497,214$ \\
\hline & $10 \%$ & $-\$ 735,012$ & $-\$ 778,248$ & $-\$ 821,484$ & $-\$ 864,720$ & $-\$ 907 ; 956$ & $-\$ 951,192$ & $-\$ 994,428$ \\
\hline & $15 \%$ & $-\$ 1,102,518$ & $-\$ 1,167,372$ & $-\$ 1,232,226$ & $-\$ 1,297,080$ & $-\$ 1,361,934$ & $-\$ 1,426,788$ & $-\$ 1,491,642$ \\
\hline
\end{tabular}

each strength priced differently and utilized/prescribed differentially, a blended price is calculated. In this illustration, the two T-Block strengths (50 $\mathrm{mg}$ and $100 \mathrm{mg}$ ) are differentially priced; it is assumed that $90 \%$ of prescriptions will be for the low dose (a weight of 0.9 ) and $10 \%$ for the high dose (a weight of 0.1 ). For this analysis, AWPs of $\$ 1.24 /$ tablet and $\$ 2.14 /$ tablet have been used for the $50 \mathrm{mg}$ and $100 \mathrm{mg} \mathrm{T}$ Block strengths, respectively. Thus,

Blended price $=[0.9 \times \$ 1.24$ (unit price $/ 50 \mathrm{mg})]+[(0.1 \mathrm{x}$

$\$ 2.14$ (unit price/ $100 \mathrm{mg}$ )]

$=\$ 58.52$

Therefore, assuming a 90\%:10\% utilization ratio, the weighted average cost-per-prescription for T-Block:

44 (estimated quantity-per-prescription) x $\$ 1.33$ (blended price of T-Block)

$=\$ 1.33$

Obviously the $90 \%: 10 \%$ utilization ratio can vary; the model allows for this through sensitivity analyses.

\section{Step 3. Determination of the cost-impact of T-Block.}

To predict the cost-impact of T-Block, the model compares the weighted average cost-per-prescription for the entire data set with and without T-Block. The relevant formula is shown below:

T-Block cost-impact (\$)

$=[$ weighted average cost-per-prescription for T-block (W)]
- [weighted average cost-per-prescription for entire data set $(\mathrm{Y})]$

$\mathrm{x}$ [T-Block prescription volume (Z)]

Parameters (W) and (Y) have been described previously. Parameter ( $Z$ ), anticipated prescription volume for the new product, is derived using this formula:

T-Block prescription volume (Z)

$=[$ total volume of CA prescriptions (annualized) \pm change in CA prescription volume]

$\mathrm{x}$ T-Block prescription market share (\%)

Through the sensitivity analyses one can observe the costimpacts, assuming changes in prescription volumes (e.g., from $-15 \%$ to $+15 \%$ ) or, for a fixed volume of prescriptions, observe the cost-impact of different T-Block market shares (e.g., $5 \%$, $10 \%$, or $15 \%$ ).

If cost-impact ( $\$$ ) is a negative number (when $\mathrm{W}<\mathrm{Y}$ ) this signals a cost savings; the model predicts a net decrease in total cost through addition of a new product to the existing formulary mix. Conversely, if cost-impact $(\$)$ is a positive number (when $\mathrm{W}>\mathrm{Y}$ ) the model predicts a net increase in total costs if a new product is added to existing formulary mix.

\section{SENSITIVITY ANALYSES}

Simple sensitivity analyses are a central component of this predictive technique, enabling the user to observe a new product's cost-impact under various conditions of uncertainty. 
Uncertainty may exist in terms of three key variables: growth (positive or negative) in the total number of prescriptions for the therapeutic category of interest; the prescription market share acquired by the new product; and the utilization ratio of its various strengths, if they are priced differently.

\section{Assumptions of the model}

The three assumptions of the model are that:

$\Delta$ product mix, as shown by historical utilization data, will remain unchanged during the evaluation period;

$\Delta$ pattern of utilization, implicit in the dataset, will continue to apply to the specified period; and

$\Delta$ prices will not change significantly throughout the evaluation period.

These assumptions are straightforward and correspond well with the model's simplicity and transparency.

Independent tests of robustness based on utilization data from several health care jurisdictions (private and public) have shown that this model is robust and that, as one would expect, the financial impact of a new product actually differs from one institution to another.

\section{RESULTS}

The data set presented here was obtained from a leading pharmacy benefit management company in the United States.

The weighted average cost-per-prescription for the entire data set was $\$ 69.86$. The average quantity-per-prescription for comparable products in the dataset was $44,44,47,43$, and 49 for Norvasc, Cardizem CD, Plendil ER, Procardia XL and Adalat CC and Calan SR, respectively, resulting in an average quantity-per-prescription for the entire dataset of 44 .

Table 4 depicts the weighted average cost-per-prescription for a new product (T-Block) assuming different utilization ratios of two strengths (50 $\mathrm{mg}$ and $100 \mathrm{mg}$ ). These weighted average costs are $\$ 58.37, \$ 62.34$, and $\$ 66.30$ for utilization ratios of $90 \%: 10 \%, 80 \%: 20 \%$ and $70 \%: 30 \%$, respectively. The corresponding estimates of savings by adopting the new product at these three assumed utilization ratios were $-\$ 1,395,454$, $-\$ 913,300$, and $-\$ 432,360$, respectively (see Table 5). ${ }^{4}$ (By convention, negative numbers represent cost savings and positive numbers indicate cost increases.)

Table 4. Estimates of the Average Cost-Per-Prescription for T-Block at Different Utilization Ratios of $50 \mathrm{mg}$ and $100 \mathrm{mg}$ Strengths

\begin{tabular}{c|c}
\hline $\begin{array}{c}\text { Utilization Ratio of T-Block } \\
\text { Strengths (50 mg and 100 mg) }\end{array}$ & $\begin{array}{c}\text { Weighted Average } \\
\text { Cost-Per-Prescription }\end{array}$ \\
\hline $90 \%: 10 \%$ & $\$ 58.37$ \\
\hline $80 \%: 20 \%$ & $\$ 62.34$ \\
\hline $70 \%: 30 \%$ & $\$ 66.30$ \\
\hline
\end{tabular}

Table 3 presents the results of a three-way sensitivity analysis, where the impact of changing the magnitude of the three variables in the model, either alone or in combination, was tested.

In our example, the individual and combined effects of changes in total number of CA prescriptions (from - $15 \%$ to $+15 \%$, in $5 \%$ increments), changes in T-Block prescription market share (at $5 \%, 10 \%$, or $15 \%$ ), and changes in utilization ratios of the $50 \mathrm{mg}$ and $100 \mathrm{mg}$ strengths (90\%:10\%, $80 \%: 20 \%$, and $70 \%: 30 \%$ ) are displayed in Table 3.

\section{DISCUSSION}

Projecting the costs of drug expenditures is a blend of science and art. As drug expenditures continue to grow disproportionately to the number of lives covered, it may be helpful to know a priori the expected financial implication of adopting a new product on formulary. In the absence of cost-effectiveness data, other simple financial modeling techniques can assist with the formulary decision process to include a new product. Our model may serve as a paragon, particularly when the therapeutic area of interest may be crowded with several variants of existing products, but where there still is room for new products to fill unmet medical needs.

Central to our model's underlying concept is the calculation of a weighted average cost-per-prescription before and after new product adoption, based on real-world historical utilization data. A weighted, rather than an arithmetic, average better reflects the mix of different products and different available strengths, which in most instances are differentially priced. The weighting factor in the adjustment of the mean is a product's or a strength's market share (\$) expressed as a proportion of total expenditures for the entire data set. As the mix of products, strengths, and their relative market shares change from one facility to another, so does the weighted average cost-per-prescription and the estimate of savings or cost increases resulting from the inclusion of a new product. Therefore, the model's weighted average concept applied to historical utilization data from a specific facility enables preparation of an exclusive cost-impact analysis. These attributes fortify the model's analytic sensitivity to variations in the mix of products from one facility to another, as well as to variations in geographic locations throughout the country.

In our example, the weighted average-cost-per-prescription for the entire calcium antagonist data set was $\$ 69.86$ before the adoption of T-Block. The average quantity of product-perprescription was 44 . Assuming a blended price of the $50 \mathrm{mg}$ and $100 \mathrm{mg}$ tablets, the weighted average cost-per-T-Block prescription was estimated to be $\$ 58.37, \$ 62.34$, or $\$ 66.30$, respectively, based on varying the utilization ratio of $50 \mathrm{mg}$ and $100 \mathrm{mg}$ strengths. Therefore, the model predicts that inclusion of T-Block will reduce the yearly cost of purchasing calcium antagonists. The reduction in costs arises from three potential sources: 1) partial displacement of one or more costly 
Table 5. Cost Impact of T-Block Following Formulary Acceptance at Different Utilization Ratios of $50 \mathrm{mg}$ and $100 \mathrm{mg}$ Strengths*

\begin{tabular}{c|c}
\hline $\begin{array}{c}\text { Utilization Ratio of T-Block } \\
\text { Strengths (50 mg and 100 } \mathbf{m g})\end{array}$ & $\begin{array}{c}\text { Savings (-) or Cost Increases (+) } \\
\text { Per Year by Adding New } \\
\text { Product on Formulary }\end{array}$ \\
\hline $90 \%: 10 \%$ & $-\$ 1,395,454$ \\
\hline $80 \%: 20 \%$ & $-\$ 913,300$ \\
\hline $70 \%: 30 \%$ & $-\$ 432,360$ \\
\hline
\end{tabular}

*Assuming 5\% market share by end of first year and no change in total number of prescriptions for calcium antagonists

products or formulations predominant in the data set; 2) partial displacement of existing price-equivalent products now being utilized at the high end of their recommended daily dose range; and 3) partial displacement of existing and lessexpensive products now utilized at multiples higher than their recommended daily doses. The results also demonstrate that the magnitude of T-Block savings will decrease (from - $\$ 1,395,454$ to $-\$ 432,360$ ) as the assumed reliance on the $100 \mathrm{mg}$ dosage formulation increases from $10 \%$ to $30 \%$ with time.

Although sales figures and market shares have been expressed in terms of Average Wholesale Prices (which are public knowledge), other price parameters (e.g, Wholesale Average Cost, Net Sales after rebates/discounts) can be used in the model. It is obvious that the more closely the price parameter reflects actual transactional prices, the more accurately the model will estimate the new product's cost impact.

As one extrapolates into the future with any given model, less and less certainty can be attached to the accuracy of costimpact projections determined by that model. For this reason, our financial model automatically annualized savings based on a single quarter. In doing so, it assumed there was no seasonality in the pattern of consumption of calcium antagonists.

This assumption is reasonable as there is no evidence of seasonal utilization of this therapeutic class, and annualizing the cost impact is consistent with managed care decision makers' desire to confine projections to one fiscal period. Where seasonality is a well-documented feature, as in oral and parenteral antibiotics in the treatment of community-acquired pneumonia, necessary adjustments need be introduced in the annualization of cost impact reflecting one quarter only.

Other than periodic price adjustments, there are three obvious sources of variability in the model. These are the utilization ratio of differentially priced strengths or formulations of a new product, year-end market shares attained by that new product, and total volume of prescriptions written for the therapeutic class. Uncertainty in terms of validity of the cost impact estimates arising from changes in magnitude of these three key variables is examined through the technique of simple sensitivity analysis. Within the limits of the model, the three-way sensitivity grid is really a summary statement showing typical financial scenarios that introducing a new product may pose.
Accordingly, cost impact estimates vary in such scenarios and the scope of results will vary from customer to customertherefore symbolizing the essence of a customized financial report.

\section{CONCLUSION}

Methods and models must be developed to predict the financial impact of new products on restricted formularies, even without extensive cost-effectiveness data. We present a robust, objective, and practical financial model that can be applied not only to calcium antagonists but also to any crowd ed therapeutic area requiring frequent formulary decisions resulting from the market entry of new compounds. In the development of this predictive cost-impact model, we have shown that simple and easily obtained drug utilization data (number of prescriptions, number of units, and average wholesale price) can be analyzed to determine the cost impact a priori of the introduction of a new compound on formulary.

\section{Trademarks}

1. Adalat and Adalat CC are registered trademarks of Bayer Aktiengesellschaft

2. Calan and Calan SR are registered trademarks of G.D. Searle $\&$ Co

3. Cardene and Cardene SR are registered trademarks of Syntex (U.S.A.) Inc

4. Cardizem, Cardizem $S R$, and Cardizem $C D$ are registered trademarks of

Carderm Capital L.P.

5. Dilacor XR is a registered trademark of Rhone-Poulenc Rorer

Pharmaceuticals Inc.

6. Dynacirc is a registered trademark of Sandoz Pharmaceuticals Corporation.

7. Isoptin and Isoptin SR are registered trademarks of Knoll Aktiengesellschaft.

8. Nimotop is a registered trademark of Bayer Aktiengesellschaft.

9. Norvasc is a registered trademark of Pfizer Inc.

10. Plendil and Plendil ER are registered trademarks of Astra Aktiebolag.

11. Procardia and Procardia XL are registered trademarks of Pfizer Inc.

12. Vascor is a registered trademark of Johnson \& Johnson.

13. Verelan is a registered trademark of the Elan Corporation.

\section{A $\quad$ References}

1. Mehl B, Santell JP. Projecting future drug expenditures-1997. Am J Health-Syst Pharm 1997; 54: 153-61.

2. Bowman GK, Moleski R, Mangi RJ. Measuring the impact of a formulary decision: Conversion to one quinolone agent. Formulary 1996; 31: 906-14 3. Gustin G, White WB, Taylor S, Daragjati, C. Clinical outcome of a mandatory formulary switch for dihydropyridine calcium channel blocker therapy at a veteran's administration medical center. Am J Hypertension 1996; 9: 312-16. 4. Summers $\mathrm{KH}_{2}$ Szeinbach SL. Formularies: The role of pharmacy-and-therapeutics (P\&T) committees. Clinical Therapeutics 1993; 15: 433-41. 